\title{
Boma to banda - A disease sentinel concept for reduction of diarrhoea
}

\author{
David J. Wolking ${ }^{1,4^{*}}$, Deana L. Clifford ${ }^{1,2,4}$, Terra R. Kelly ${ }^{1}$, Enos Kamani ${ }^{3}$, Woutrina A. Smith ${ }^{1,4}$, \\ Rudovick R. Kazwala ${ }^{3,4}$ and Jonna A.K. Mazet ${ }^{1,4}$
}

\begin{abstract}
Diarrhoeal diseases can be debilitating, especially for children and young animals. In many rural areas, particularly pastoral communities, livelihoods are characterized by close interaction between household members and their livestock herds, and children often care for young animals, creating opportunities for the transmission of multiple zoonotic pathogens. Using a One Health approach, we first evaluated whether diarrhoeal diseases were a problem for pastoral households in Tanzania and then investigated their calf herds to identify the prevalence and risk factors for diarrhoeal disease and the shedding of the zoonotic pathogens Cryptosporidium and Giardia. Sixty percent of households reporting cases of human diarrhoea also had diarrhoea detected later in their calf herds, and calf herds shedding Cryptosporidium oocysts were six times more likely to be diarrhoeic. Because Cryptosporidium shares a similar transmission mode with a wide range of diarrhoeagenic organisms and calf diarrhoea outbreaks can involve multiple pathogens with mixed infections, it is possible that calf diarrhoea may be indicative of shared risk of zoonotic pathogens from environmental contamination. To mitigate the risk of transmission of faecal-borne zoonotic pathogens from herds to households (boma-livestock pens to banda -household building), we describe a conceptual disease early-warning method proposing diarrhoeic calves as animal sentinels. Such a calf warning system, combined with appropriate interventions designed to minimize exposure, could serve as a practical solution for reducing risks of diarrhoeal diseases among animals and people.
\end{abstract}

Keywords: Zoonoses, Disease surveillance, Diarrhoea, Cryptosporidium, Giardia, Health, One Health, HALI Project, Tanzania, Animal sentinels

\section{Background}

For many in the developing world, diarrhoeal disease is a constant and debilitating part of life with devastating impacts on health, nutrition and economic productivity (Everhart 1994; UNICEF 2009). For children, it is especially threatening. Kotloff et al. (2013) found that children with moderate to severe diarrhoea are 8.5 times more likely to die when compared to children without diarrhoea, especially in the first two years of life. Yet humans do not bear the burden of diarrhoeal disease alone; young livestock, especially neonates, are highly susceptible and diarrhoea is a leading cause of calf morbidity and mortality worldwide (Kasle 2008; Wudu et al.

\footnotetext{
* Correspondence: djwolking@ucdavis.edu

'One Health Institute, School of Veterinary Medicine, University of California,

Davis, 1089 Veterinary Drive, Davis, CA, USA

${ }^{4}$ Health for Animals and Livelihood Improvement (HALI) Project, http://

www.haliproject.org

Full list of author information is available at the end of the article
}

2008). Though diarrhoea is a preventable and treatable condition, options for people and livestock are limited in many rural areas by water quality and availability, sanitation infrastructure and access to medical/veterinary services (Richards et al. 1993; Cheneau et al. 2004; UNICEF 2009). Furthermore, diarrhoeal disease is often underreported due to lack of recognition or respondent bias, as discussing defecation is considered taboo in many cultures (Bongartz et al. 2011; Bwire 2011).

Diarrhoea in both humans and animals has a complex, multifactorial aetiology, involving pathogen exposure along with a wide range of environmental, management and nutritional factors (Donowitz et al. 1999; Barrington et al. 2002). Cryptosporidium is a common cause of protozoal diarrhoea in humans and calves worldwide, with significant morbidity and mortality in the developed and developing world, especially among the immunosuppressed (Fayer et al. 1998; Olson et al. 2004; Snel et 
al. 2009; Kotloff et al. 2013). In a recent multi-site study, Cryptosporidium ranked second among four pathogens associated with increased risk of death from moderate to severe diarrhoea in children in the first two years of life, with most deaths occurring outside health facilities and in rural areas (Kotloff et al. 2013). Human infection with protozoal pathogens has been associated with close contact with livestock (Hunter et al. 2004; Siwila et al. 2007), but exposure can be minimized through management practices targeting a reduction in transmission, including the isolation of sick animals, reduced contact with manure, water treatment/filtration and good hygiene (Barrington et al. 2002).

In the arid and semi-arid areas of sub-Saharan Africa, traditional pastoral and agro-pastoral livestock production is characterized by close contact between human and animal populations, representing a viable subsistence and livelihood strategy (Thornton et al. 2002). Although close contact may increase transmission of zoonotic pathogens, it encourages high visibility and awareness of herd condition, creating opportunities for passive disease surveillance, assessment of herd health and early disease intervention. Many pastoralist groups, such as the Maasai and Barabaig in East Africa, have developed effective ethnoveterinary diagnostic and surveillance practices, as disease treatment and control options are limited (Minja 1994; Jacob et al. 2004). In these systems, attention to calf health is a critical component of traditional husbandry practices, though little attention has been paid to calf illnesses like diarrhoea in disease surveillance.

Human and animal health are intrinsically connected in pastoralist culture, and both populations share similar risks of exposure to pathogens. Because many diarrhoeic pathogens like Cryptosporidium and Giardia are zoonotic, (organisms that can be transmitted between animals and people), monitoring herds for diarrhoeal disease may improve understanding of exposure risks. Animal sentinels have been proposed as practical substitutes for resource-intensive surveillance systems to detect and provide early warning of the presence of pathogens, changes in the prevalence or incidence of disease/pathogens over time and to trigger disease response and control efforts (Rabinowitz et al. 2009; McCluskey 2003). Because calves are both highly susceptible to diarrhoeal disease and are closely monitored and managed by caretakers, we believe they have the potential to function as early-warning sentinels for diarrhoeal pathogens in a pastoral management system.

As part of a long-term disease surveillance and monitoring project aiming to better understand the epidemiology and impacts of zoonotic diseases on people, animals and the environment in the Ruaha ecosystem of Tanzania, we surveyed pastoral households on human health risks to assess if diarrhoeal diseases were a problem. We then later conducted a focused and intensive evaluation of calves in a subset of these households to determine the prevalence of and risk factors for diarrhoeal disease and Cryptosporidium and Giardia shedding, while also assessing household animal care and hygiene practices through a targeted risk factor questionnaire. By considering the findings from the human health survey with those from the calf-focused investigation, we hoped to gain meta-insight on potential environmental and shared risks of zoonotic transmission between herds and households. In addition, we conceptually explored the potential for calves to serve as sentinels for diarrhoeal disease risk. Our aim is to propose some practical options for evaluation that might improve prevention of zoonotic pathogen transmission from herds to households (boma - livestock pen to banda household building).

\section{Study area}

The study area, described in detail by Mazet et al. (2009), is located in the eastern portion of the Ruaha ecosystem of central Tanzania. The long-term study was conducted in rural villages in the Idodi and Pawaga Divisions of Iringa District, a semi-arid region where pastoral livestock production contributes significantly to livelihoods (Figure 1). The target zoonotic pathogens for this study, Cryptosporidium parvum and Giardia lamblia, have been detected in local surface water sources and in faecal samples from wildlife and livestock inhabiting the area (Miller et al. 2010).

\section{Methods}

\section{Sample population}

The target population consisted of pastoral and agropastoral livestock-owning households belonging to the Maasai, Barabaig and Sukuma ethnic groups in Idodi and Pawaga. An initial cross-sectional socioeconomic and disease survey (hereafter referred to as the 'human health survey') of 159 agro-pastoralist and pastoralist households in 21 villages of the Ruaha ecosystem was conducted in December 2006 and November 2007. Households were selected using the discriminate sampling technique (Strauss and Corbin 1998), and interviews were conducted in Kiswahili with the head of the household as described by Masozera (2010). Data from this survey were collected for multiple objectives related to the long-term study and featured themes on animal production and health, economics, livelihoods and household health, a component of which included data on reported diseases like diarrhoeal diseases and reasons for visits to health clinics.

From the human health survey, we generated a representative subset of 60 of the households retaining variation in ethnicity, socioeconomic status and geographic 


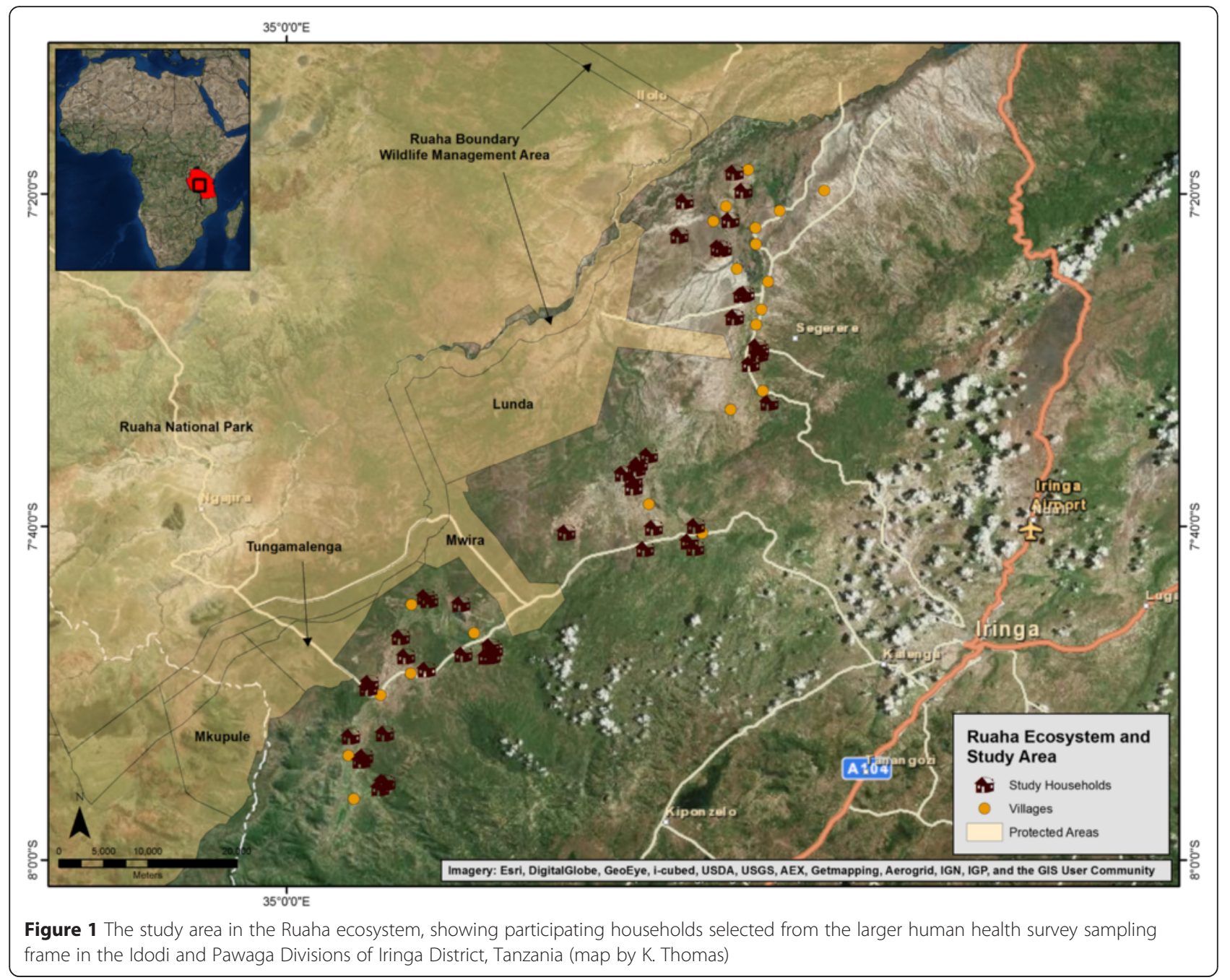

location. Our intent was to evaluate whether diarrhoea was also a health problem for calves and a potential pathogen transmission risk to livestock-keeping households. In practice, we could confirm that 44 of these households were available for follow-up with 16 additional pastoralist households included in the calffocused study at the same sites as the targeted households but without confirmation of their participation in the human health survey. Pastoralist communities are very dynamic, with frequent household movement and turnover. We chose to sample these unconfirmed households at the same sites for zoonotic pathogens in their calves to maintain a rigorous sample size for prevalence estimates for the long-term study.

The goal of the calf-focused survey was to sample at least 300 calves, allowing for calculation of prevalence estimates for Cryptosporidium and Giardia with 5 to $10 \%$ tolerable error over all potential prevalence ranges. As calf herd size varied from 1 to over 100 animals, the herds were sampled proportionately. Within each herd, we aimed to sample a minimum of five calves: in households with five or fewer calves, every animal was sampled, and in households with more than five calves, we sampled at least $25 \%$ of the calf herd. Our proportional sampling approach allowed us to detect diarrhoea and correctly classify a herd as positive for diarrhoea at least $95 \%$ of the time if at least $20 \%$ of the calves were diarrhoeic (Sergeant 2015). Additionally, five calves per household was estimated to be adequate for determining the presence or absence of the protozoa in each calf herd (Scheaffer et al. 2006); herds were considered to be 'positive' for Cryptosporidium or Giardia if at least one calf was shedding; otherwise, the herd was considered 'negative.'

\section{Data collection}

Data on human health and diarrhoea were obtained from the 2006 to 2007 cross-sectional human health survey (Masozera 2010). From this data set, we explored visits to health centres (e.g. nearest health centre 
location and time and reason for visitation by any household members on the last visit) and the prevalence of reported human diarrhoea among the 44 confirmed, continuing households recruited for the calf-focused survey conducted the following year. Additionally, we explored survey response data on household water source and treatment practices and general hygiene and sanitation (e.g. water source used for drinking, cooking, bathing; use and type of toilet; and waste management). Our aim was to determine if diarrhoeal disease was a health problem in the pastoral community using the first survey instrument and then to conduct a follow-up investigation of behaviours and factors associated with general risks of zoonotic disease transmission focusing on common exposure pathways for diarrhoeal pathogens that could be shared between and among people and their animals.

The second survey phase, involving cross-sectional calf sampling and household interviews at 60 households (44 confirmed from the initial human health survey), was conducted between August 2008 and January 2009. The methodology applied was designed to further explore diarrhoeal disease in the community by focusing on herds and the animals managed in closest proximity to the home environment and the animals with the most frequent and intimate contact with household members: calves, their dams and small ruminants.

During the calf-focused survey, calf faecal samples were collected directly from the rectum and preserved in $2 \%$ buffered formalin until testing. Individual animal data (age, sex, weaning status) along with the presence (or absence) of clinically apparent diarrhoea were recorded for each sampled calf. Calves were herded into bomas (fenced corrals) for random sampling, though in cases where animals could not be moved into bomas, convenience sampling was employed based on the team's ability to capture the animal. In calf herds numbering five or fewer $(n=11)$, every calf was sampled; a mean of $54 \%$ of calves were sampled in larger herds, ranging from 6 to 130 calves $(n=49)$. In total, faecal samples from 312 calves were collected, with 262 samples from 52 of the 60 households available for analysis due to sample loss during storage thereby reducing the sample size of the calf sampling and herd-focused survey to 52 households.

Informed consent was obtained from all study households, and following animal sampling, the head of each household or main caretaker of young livestock was interviewed using a standardized 35-question Kiswahili questionnaire. Factors hypothesized to be associated with the risk of Cryptosporidium and Giardia infection in calves were examined after a review of the literature (Fayer et al. 1998; Huetink et al. 2001; Delafosse et al. 2006), and the questionnaire also included questions about herd health, general livestock and calf management practices (including management of calves, kids and lambs, as young stock are generally maintained as a single herd in this system) and veterinary practices (including treatment of sick animals). Questions regarding household interaction and contact with the animals and household hygiene and sanitation practices were also posed to obtain information on potential zoonotic disease transmission risks. Where possible, responses were confirmed through visual observation.

\section{Laboratory analysis}

Faecal samples were prepared on direct fluorescent antibody slides and stained with Cryptosporidium- and Giardia-specific fluorescent-labelled antibodies using the A100FLK Aqua-Glo ${ }^{\mathrm{Tm}}$ Giardia/Cryptosporidium Direct Comprehensive Kit (Waterborne Inc., New Orleans, LA, USA). Relative Cryptosporidium oocyst and Giardia cyst shedding was quantified by visually counting fluorescing oocysts and cysts in all fields $(\times 1,000)$ of the slide well. Samples were recorded as negative when no oocysts or cysts were observed on the stained slide. We used the shedding intensity of Cryptosporidium and Giardia by individual calves to estimate environmental loading rates and public health risk associated with the pathogens. Visual quantification of oocysts and cysts in the slide wells was used to obtain the numbers of oocysts and cysts per gram of faeces using the methodology developed by Xiao and Herd (1993), and we used scaling of these estimates to calculate the mean oocysts and cysts per kilogram of excreted faeces per day following the calculations developed by Atwill et al. (2003).

\section{Data analysis}

Human health data obtained from the initial human health survey were evaluated at the household level using descriptive statistics. Because of the time interval between the collection of data on human diarrhoeal disease in the 2006 to 2007 survey and the calf sampling and household interview activities conducted in 2008 to 2009, no statistical comparisons were made among the human and calf health data. Rather, these data were used to gain insight into health problems among pastoralists including diarrhoeal disease and to identify risks and exposure pathways for zoonotic diarrhoeal disease transmission that when evaluated in conjunction with data from the calf-focused survey would enable identification of opportunities for shared disease risks among humans and animals.

Diarrhoea prevalence, Cryptosporidium and Giardia shedding prevalence and the respective $95 \%$ exact confidence intervals were estimated for calves at the herd level. Shedding prevalences were estimated for Cryptosporidium and Giardia based on microscopy-positive 
animals. To investigate how diarrhoea and pathogen shedding varied among individual calves, calf-level data were used to assess the correlation between age and Cryptosporidium or Giardia shedding intensities using the Spearman rank correlation coefficient and to evaluate the associations between age groups and calf diarrhoea or Cryptosporidium or Giardia shedding using univariable logistic regression models. Variables hypothesized as risk factors were then evaluated for association with calf diarrhoea and Cryptosporidium and Giardia shedding at the herd level using univariable logistic regression models, including herd management practices (e.g. moving bomas and manure management); calf birthing and husbandry practices; veterinary and ethnoveterinary practices; water sources for herds and households; mixing of herds; and herd size and distance from water sources, villages, protected areas and road networks. Variables associated with calf diarrhoea and Cryptosporidium or Giardia shedding in univariable models $(P \leq 0.20)$, potentially confounding variables and biologically plausible interactions were then evaluated in multivariable logistic regression models. Final parsimonious models were selected by comparing Akaike's Information Criterion (AIC) among competing nested and non-nested models. The final model fit was evaluated by Hosmer-Lemeshow goodness-of-fit tests and graphical residual diagnostics (Hosmer and Lemeshow 1989). For multivariable models, adjusted odds ratios with $95 \%$ confidence intervals were estimated to assess the strength of the association between each risk factor and calf diarrhoea or shedding status. All statistical tests were performed with R statistical software (R Core Development Team 2013, Vienna, Austria).

\section{Results}

\section{Human health survey}

Of the confirmed households from the 2006 to 2007 human health survey participating in the calf-focused survey $(n=44)$, $9 \%(4 / 44)$ reported cases of human diarrhoea in the two-week period preceding the interview, two $(50 \%)$ of which involved children under the age of seven. Three $(7 \%)$ households reported a family member travelling to a local health centre for treatment of diarrhoea on their last visit (all three cases within the past 30 days), a journey ranging from $10 \mathrm{~min}$ to four hours on foot (mean $=90 \mathrm{~min}$ ). Among the surveyed households reporting visits to a health centre $(n=34)$, diarrhoea emerged as the third most frequent symptomatic cause for visitation ( $9 \%$ ), behind fevers (44 \%, $15 / 34)$ and malaria $(24 \%, 8 / 34)$.

\section{Calf-focused survey}

Forty percent (21/52) of households reported diarrhoea in their calf herds, while the trained interviewer observed diarrhoea in $54 \%(28 / 52)$ of calf herds; in addition, $61 \%(17 / 28)$ and $86 \%(24 / 28)$ of diarrhoeic calf herds contained at least one animal shedding Cryptosporidium or Giardia, respectively (Table 1). Calf herds containing at least one diarrhoeic animal were identified in $53 \%(22 / 42)$ of households that reported sheltering of sick animals within the human living quarters. In addition, calves shedding Cryptosporidium or Giardia were identified in $41 \%(17 / 42)$ and $74 \%$ $(31 / 42)$ of these same households, respectively (Table 1).

Overall, $42 \%(22 / 52)$ and $75 \%(39 / 52)$ of the calf herds sampled contained at least one animal shedding Cryptosporidium oocysts or Giardia cysts, respectively. The odds of calf diarrhoea significantly decreased with increasing herd size $(\mathrm{OR}=0.98$, CI 0.96 to 0.99; Table 2). None of the evaluated risk factors were statistically associated with Giardia shedding.

Because Cryptosporidium shedding was significantly associated with calf diarrhoea, risk factors for Cryptosporidium shedding were assessed in a multivariable logistic regression model. Herds positive for Cryptosporidium were eight times more likely to have diarrhoea compared to herds not shedding Cryptosporidium (CI 1.98 to 33.94; Table 3). In addition, households that reported moving their bomas when full of manure or in response to rain were 23 times more likely to have calves shedding Cryptosporidium than households that did not move their bomas (CI 2.40 to 220.17; Table 3).

Several household-level management and hygiene factors were evaluated as potential protective measures to reduce the risks associated with diarrhoea and zoonotic disease transmission in both surveys. From the calffocused survey, $82 \%(42 / 51)$ of households reported sheltering young and sick animals inside the home, and $87 \%$ (45/52) reported women and children as the primary caretakers for young and small stock. In general, $96 \%(50 / 52)$ of these respondents reported hand washing as a consistent preventive practice when working with animals. Yet among those reporting hand washing, relatively few respondents reported hand washing when separately prompted about preventive practices during specific activities likely posing the greatest risk for exposure to faecal pathogens in calves, such as calving (46 \%, 23/50), milking $(14 \%, 7 / 50)$ and working with manure $(4 \%, 2 / 50)$.

In the human health survey, $95 \%(43 / 44)$ of households reported using surface water as their primary water source for human consumption, while only $39 \%$ (17/44) reported treating water for household consumption. Later during the calf-focused survey, when asked about water use for their herds, $90 \%$ (47/52) reported surface water use as the primary water source for livestock, with $83 \%$ (43/52) also reporting surface water as the primary water source for their calf herds. 
Table 1 Prevalence (observed and reported) of calf diarrhoea and Cryptosporidium and Giardia shedding, and associated herd and household characteristics from the calf-focused survey (2008 to 2009)

\begin{tabular}{|c|c|c|c|c|c|}
\hline \multirow[t]{2}{*}{ Case description } & \multirow[t]{2}{*}{ Number } & \multirow{2}{*}{$\begin{array}{l}\text { No. of households } \\
\text { (prevalence) }\end{array}$} & \multicolumn{3}{|c|}{ Corresponding no. of households with } \\
\hline & & & Calf diarrhoea & Cryptosporidium shedding & Giardia shedding \\
\hline Diarrhoea observed in at least one calf in the herd & 52 & $28(53.9 \%)$ & NA & $17 / 28(60.7 \%)$ & $24 / 28(85.7 \%)$ \\
\hline $\begin{array}{l}\text { Households sheltering young and sick animals inside } \\
\text { the home }\end{array}$ & 51 & $42(82.3 \%)$ & $22 / 42(52.4 \%)$ & $17 / 42(40.5 \%)$ & $31 / 42(73.8 \%)$ \\
\hline $\begin{array}{l}\text { Households reporting women and children as the } \\
\text { primary caretakers for young and small animals }\end{array}$ & 52 & $45(86.5 \%)$ & $26 / 45(57.8 \%)$ & 20/45 (44.4\%) & $36 / 45(80.0 \%)$ \\
\hline
\end{tabular}

\section{Individual calf sampling}

Of the 262 calves sampled across all households, $17.2 \%$ had clinically apparent diarrhoea. Calf shedding prevalence for Cryptosporidium was estimated at $9.9 \%$ (CI 0.063 to 0.135$)$ while Giardia shedding prevalence was estimated at $22.9 \%$ (CI 0.178 to 0.28 ). Calves $\leq 3$ months old were two times (CI 1.09 to 4.76) more likely to have diarrhoea than older calves ( $>3$ months old). In addition, calves $\leq 3$ months old were significantly more likely to be shedding Cryptosporidium (OR = 4.94, CI 1.61 to 20.34) and Giardia (OR $=2.68$, CI 1.38 to 5.45$)$ compared to older calves. Further, calf age and intensity of shedding Cryptosporidium oocysts rho $=-0.149(P=0.0158)$ and Giardia cysts rho $=-0.135(P=0.0281)$ were negatively correlated, providing evidence that younger calves also shed more oocysts and cysts. Faecal shedding intensity estimates for Cryptosporidium ranged from 100 to 106,000 oocysts per gram of faeces (median $=450$ ), while Giardia ranges were higher, from 200 to 194,600 cysts per gram (median $=3,150$ ). Median environmental loading rates in excreted faeces were estimated at 1,800,000 oocysts and 156,879,350 cysts per calf per day for Cryptosporidium and Giardia, respectively, for acutely infected calves.

\section{Discussion}

\section{Human and animal health risks}

The reported presence of diarrhoea in the human population, especially among children, as well as the evidence that individuals do seek treatment for diarrhoea at local health centres despite long walking distances, indicates that diarrhoea is a recognized health problem among pastoralists in Ruaha. It is likely that reported prevalence for human diarrhoea is also lower than actual prevalence, as individuals may be resistant to sharing personal

Table 2 Significant univariable logistic regression model estimates for risk factors for diarrhoeal disease in calf herds

\begin{tabular}{lccl}
\hline Risk factor & $\begin{array}{l}\text { Unadjusted } \\
\text { odds ratio }\end{array}$ & $\begin{array}{l}P \text { value } \\
(0.05)\end{array}$ & $\begin{array}{l}95 \% \text { confidence } \\
\text { interval }\end{array}$ \\
\hline Herd size & 0.98 & 0.020 & $0.96,0.99$ \\
$\begin{array}{l}\text { Cryptosporidium } \\
\text { (herd positive) }\end{array}$ & 5.66 & 0.005 & $1.48,25.45$ \\
\hline
\end{tabular}

health information, especially with regard to defecation, and may be unaware of the health status of family members for similar reasons.

The reported high prevalence of diarrhoea in livestock, combined with our observations that $54 \%$ of sampled herds had one or more calves with clinical diarrhoea, shows that just as with people, diarrhoeal disease is an important veterinary problem. Reported calf diarrhoea underestimated actual prevalence determined by our trained interviewer by approximately $14 \%$, likely because the trained interviewer recorded all cases of clinically apparent diarrhoeal disease. As calf diarrhoea appears relatively common in these herds, attention to calves with diarrhoea may not be a common practice. The willingness to openly discuss animal diarrhoea, however, appears to bypass cultural sensitivity around the topics of faeces and defecation, indicating diarrhoea in animal sentinels may be a useful topic for introducing discussions of diarrhoeal disease risk in people, especially from zoonotic pathogens.

In this pastoral system, small stock and young animals are managed in close proximity to adult livestock bomas (pens), typically located adjacent to bandas (dwellings). The reported sheltering of young and sick livestock within the human living quarters for protection and observation, along with the care of these same animals by women and children, demonstrates the intimate connection between calves and susceptible caretakers (Figures 2 and 3). As demonstrated, calf herds with diarrhoea were eight times more likely to be shedding Cryptosporidium and should be considered a human health risk, especially considering Cryptosporidium's low infective dose to people (as few as 30 oocysts or cysts, far less than what a naturally infected calf would excrete into the

Table 3 Multivariable logistic regression model estimates of the association of risk factors with Cryptosporidium shedding in calf herds

\begin{tabular}{lcrrl}
\hline Risk factor & $\begin{array}{l}\text { Odds } \\
\text { ratio }\end{array}$ & Estimate & $P$ value & $\begin{array}{l}95 \% \text { confidence } \\
\text { interval }\end{array}$ \\
\hline Intercept & 0.018 & -4.05 & 0.001 & $0.002,0.19$ \\
Diarrhoea & 8.21 & 2.11 & 0.007 & $1.98,33.94$ \\
Moving bomas & 22.99 & 3.14 & 0.007 & $2.40,220.17$ \\
\hline
\end{tabular}




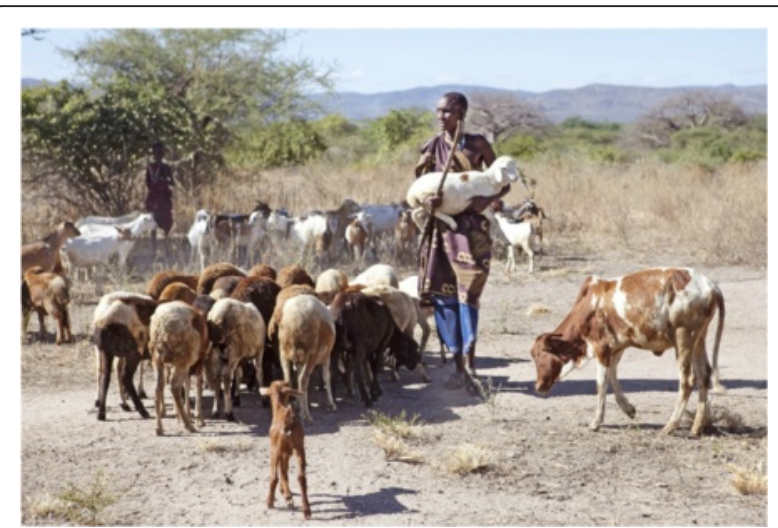

Figure $\mathbf{2}$ In the study area, as in many pastoral communities, young and small livestock are often managed in close proximity to the home and are frequently cared for by women and children,

increasing the potential for zoonotic disease transmission between these vulnerable and susceptible populations (photo by M. Richmond)

environment), the relatively high estimated faecal loading potential of a shedding calf and the high survival and resilience of Cryptosporidium oocysts in the environment (DuPont et al. 1995; Zambrisky et al. 2013; Ryan et al. 2014). Further, younger calves have been described as more likely to be infected with and shedding the zoonotic species of Cryptosporidium, C. parvum, (Smith et al. 2014). Because younger calves in our study were more likely to have diarrhoea, they may also be more likely to shed zoonotic parasites of public health concern compared to host-specific genotypes like C. andersonii that are more often shed by older animals.

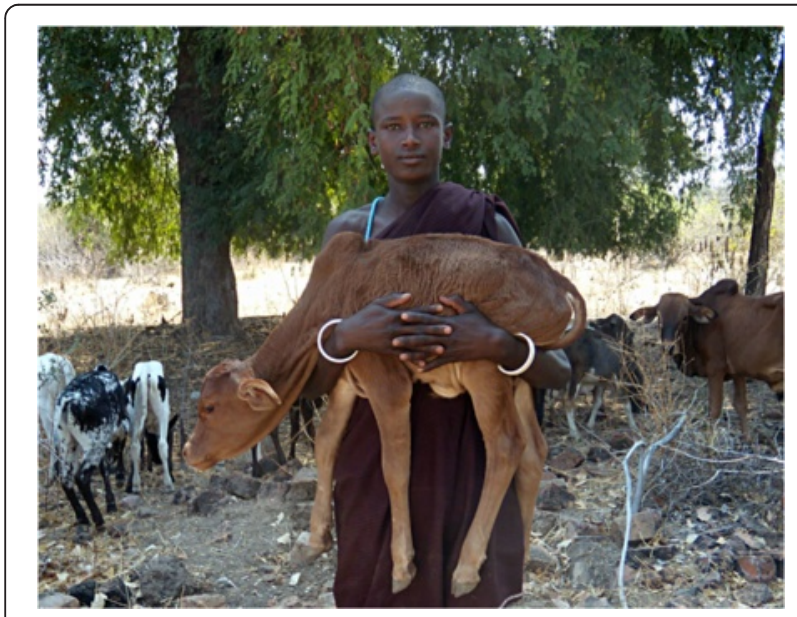

Figure $3 \mathrm{~A}$ herder holds a calf from his herd. In pastoralist communities, calves are often managed in small herds kept close to the household for protection and care. This practice provides an opportunity for use of calves as disease sentinels as they are under close observation and monitoring by caretakers (photo by D. Wolking)

\section{Calves as sentinels for diarrhoeal diseases}

Because disease surveillance and health services for both human and animal populations in the study area are underdeveloped (Mfinanga et al. 2009), communitybased surveillance coupled with practical disease management options could be an effective next step for disease control. A calf-based sentinel method (Figure 4) could provide utility as a household-level sentinel for diarrhoeal disease risk and potential transmission reduction by providing early warning of potential presence of pathogens, like Cryptosporidium.

According to a conceptual framework developed by Halliday et al. (2007), animal sentinels must be susceptible and responsive to a zoonotic pathogen that is spatially or ecologically related to a target population, in this case household members. To be effective as an early-warning sentinel, response must occur prior to the exposure of the target population or must enable a rapid response to pathogen presence if exposure has already occurred (Halliday et al. 2007). While determining the point and timing of exposure (animals or humans) in the study community is out of the scope of this study, the Halliday framework still holds relevance for an animal sentinel concept in a pastoral management system. Calves, due to their inherent value and economic importance in the pastoral production system, are a highly visible group from a management perspective and are closely monitored by caretakers. In addition, among other livestock, the prevalence of diarrhoea in calf herds, especially young calves, was higher than that reported for adult animals, demonstrating a calf herd's greater sensitivity and therefore potential utility as an earlywarning sentinel.

We assessed Cryptosporidium as a model pathogen for our risk reduction concept due to its transmission ecology, zoonotic potential and diarrhoeic effect on susceptible animals. Cryptosporidium was detected at relatively high prevalences at the herd level compared to other studies in the region (Tanzania Ministry of Agriculture and Food Security 2002; Kusiluka et al. 2005), and Cryptosporidium shedding was associated with an increased risk of diarrhoeal disease in neonatal calves. Because Cryptosporidium shares a similar transmission ecology to a wide range of zoonotic faecal-oral diarrhoeagenic organisms, it could serve as a proxy for many other diarrhoea-causing pathogens. It should be noted that we are not proposing a calf sentinel system as a solution for the surveillance or detection of diarrhoeagenic zoonotic pathogens, rather that the calf sentinel concept could be explored as practical option for visually identifying potential presence of zoonotic pathogens in order to implement risk reduction measures in areas where professional health and diagnostic services are unavailable. 


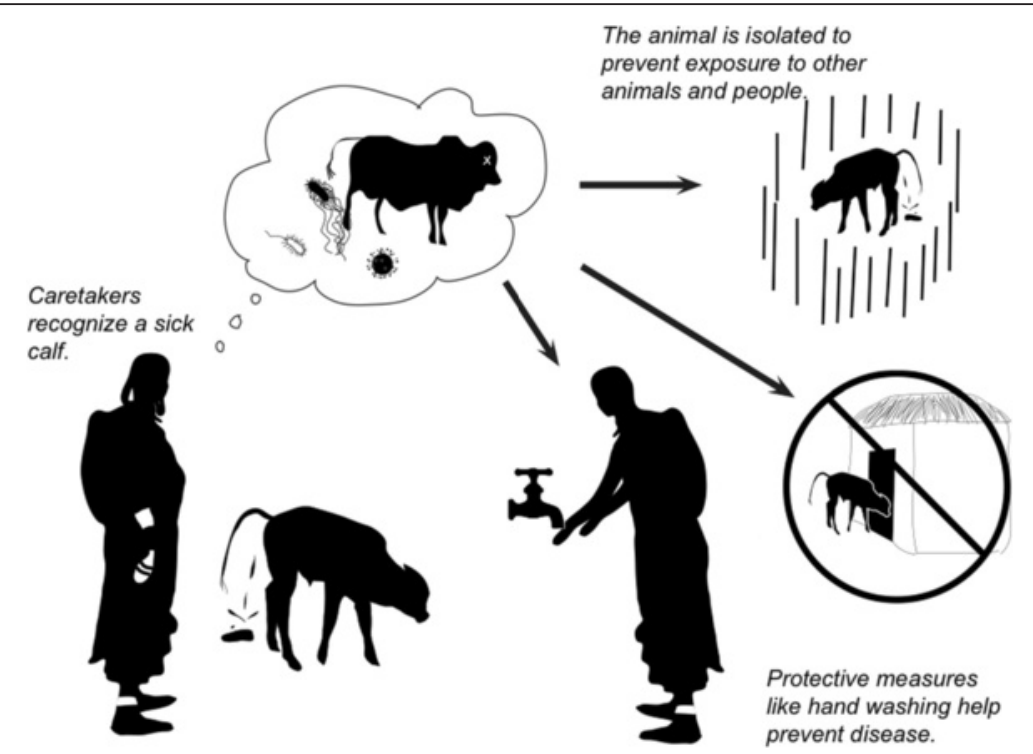

Figure 4 Diagram of the proposed calf sentinel concept. Caretakers could recognize a calf with diarrhoea and through basic educational interventions, associate the animal with potential presence of diarrhoeal disease-causing pathogens, like Cryptosporidium. Once the potential risk is identified, to protect the herd and household from exposure, caretakers could isolate the sick animal and dam (if milking) from both the herd and household and emphasize basic protective measures like hand washing after working with animals and before eating to prevent disease transmission (illustration by A. Kent)

Despite obvious limitations, this study demonstrates that diarrhoea observed in calves may be indicative of shared risk between animals and humans where zoonotic pathogens like Cryptosporidium are present in the local environment. Further, there may be utility in evaluating a syndromic-based sentinel method like the calf sentinel concept in areas under-served by public and veterinary health systems, so as to determine what impact the method could have in early disease identification, reporting, prevention and control. Because of taboos (Bongartz et al. 2011; Bwire 2011), it is possible that pastoralist households would more proactively monitor calves for visual signs of an increase in incidence of diarrhoea rather than communicate with one another about cases of human diarrhoea. If further studies evaluating the complex aetiology of diarrhoea in human and animal populations do indeed identify a shared zoonotic pathogen and transmission pathway, the calf sentinel system could be a very valuable alternative to unavailable health services. This system would enable the alerting of households and communities to the potential presence of infectious agents.

The use of any surveillance system is practical only if its economical application results in early detection and preventive response, leading to disease control (Doherr and Audige 2001). In sub-Saharan Africa, disease surveillance systems lack resources, capacity and coordination, all of which reduce their capability for disease detection and control (Nsubuga et al. 2002; Shears 2000). Furthermore, these disease surveillance systems are often costly and impractical to implement in rural areas and, as a result, are often passive and dependent on medical and veterinary centre caseload (Shears 2000; Halliday et al. 2007). To be effective, passive surveillance systems require high stakeholder participation, as well as trust and communication with official government surveillance networks (Doherr and Audige 2001). These are challenging elements to encourage in rural areas and among pastoralist communities. Sentinel surveillance, on the other hand, could encourage disease detection at the source, drastically improving early warning and minimizing potential impacts of infectious diseases. Empowering households with the knowledge and appropriate tools to recognize and respond to public health threats like calf diarrhoea could lead to disease reduction and improved health and livelihoods.

\section{Diarrhoeal disease control strategies for pastoral areas}

In our study, the practice of moving bomas was significantly associated with Cryptosporidium shedding and was reported as a response to precipitation and as a preventive disease measure. We suggest that movement of the boma may instead be a practical response to disease. Manure management, including possibly more frequent movement from faecally contaminated areas, is recommended as a disease prevention and control strategy when coupled with basic sanitation measures, especially as so few respondents reported hand washing following work with manure. It should also be noted that $33 \%$ of households reported no access to improved latrine 
facilities, using the surrounding environment for defecation. While not investigated in this study, human faeces can also contribute to pathogen contamination and shared transmission risk among animals and household members, and adoption of safe stool disposal practices (latrines, burying, etc.) has been shown to decrease diarrhoeal disease incidence (Curtis et al. 2000). Therefore, safe disposal of human faecal waste, along with basic sanitation measures, such as hand washing with soap following defecation and before eating and after working with animals and manure, are highly recommended practices.

From a herd management perspective, isolating diarrhoeic animals, especially young calves, from the remainder of the herd and household members is recommended to minimize environmental exposure. Isolation measures could be implemented through the construction of smaller individual animal pens or stables. The sheltering of sick young animals inside the home should also be discouraged, as it may increase the risk for human pathogen exposure.

The vast majority of households in our study relied on surface water for both herd and household use. Given that both Cryptosporidium and Giardia have been identified in water sources in the area, water may play a role in diarrhoeal disease transmission and is especially critical to address from a public health perspective (Graczyk et al. 1997; Tumwine et al. 2002). To best minimize the waterborne risk of transmission, it is recommended that appropriate options for water treatment at the point of use be made available to households and that water supplies for the household and livestock be kept as separate as possible to prevent contamination.

Finally, we recommend that future studies investigating zoonotic pathogens in pastoral areas incorporate surveillance of both people and animals, as well as assessment of environmental influences, to better characterize the shared health and transmission risks between these closely interconnected populations. Additional research is needed both on the presence and prevalence of disease among pastoral populations; more research is also needed on the molecular epidemiology of the zoonotic pathogens that pastoralists share with their livestock and other animals. Because disease controls and intervention options in these pastoral areas are often limited, emphasizing applied and transdisciplinary approaches to disease detection, prevention and control will go a long way in improved targeting of interventions, extension efforts and policies designed to work with actual limitations and resource constraints.

\section{Conclusions}

Our study represents one of the first attempts to investigate diarrhoeal diseases among pastoral livestock producers using a One Health approach. This multidisciplinary approach is uniquely positioned to assess health risks from the environment, animals and people, enabling the identification of more comprehensive and potentially effective prevention and control strategies.

Our findings show that diarrhoea is both a human health and veterinary problem in the study area and that diarrhoeic calves pose a risk to human and animal health.

Managing diseases that can be shared between animals and people in marginalized environments with poor access to professional health services, like pastoral areas, requires novel and practical approaches along with efforts to evaluate their potential. We propose that calf sentinels may be a low-cost and easily implementable concept for further evaluation to reduce diarrhoeal disease risks for animals and people. While we encourage additional efforts to explore animal sentinels for disease risk reduction, complementary education interventions should also be encouraged. These education interventions to improve awareness of shared risks associated with zoonotic diseases, like those shown in our study, would improve knowledge of the causes of disease in animals and humans, along with transmission pathways, prevention and control strategies. Linked risk reduction and education interventions could also strengthen linkages between households and formal medical and veterinary reporting networks, potentially leading to improved disease communication and health information flows between health professionals and the communities they serve.

\section{Competing interests}

The authors declare that they have no competing interests.

\section{Authors' contributions}

The International Committee of Medical Journal Editors (ICMJE) criteria for authorship were read and met by all authors. DJW, DLC, RRK and JAKM conceived of the study design and coordinated the study under DJW's supervision. DJW conducted the fieldwork, collected the samples and implemented all surveys. DJW, EK and RRK carried out the diagnostics and pathogen testing. DJW, DLC, TRK and JAKM performed the statistical analysis. DJW wrote the first draft of the manuscript, and DLC, TRK, RRK and JAKM contributed to the manuscript revisions. All authors read and approved the final manuscript.

\section{Authors' information}

The Health for Animals and Livelihood Improvement (HALI) Project is a collaborative research and capacity building programme investigating health at the human-animal-environment interfaces in Tanzania. HALI is led by JAKM, Executive Director of the One Health Institute, University of California, Davis, and RRK, Professor at the Faculty of Veterinary Medicine and Public Health, Sokoine University of Agriculture.

DJW, (BA, MSc), is a scientist, and Senior Manager for Global Programs at the UC Davis One Health Institute. His research interests are the epidemiology of zoonotic pathogens at the human-animal-environment interface and the impacts of behaviour on health, disease emergence and transmission.

DLC, (DVM, MPVM, PhD), is a veterinarian for the California Department of Fish and Wildlife and Assistant Adjunct Professor for the UC Davis School of Veterinary Medicine. DLC supported the development of the HALI Project, 
and her research focuses on disease surveillance and wildlife and the epidemiology of zoonotic pathogens at the human-animal-environment interfaces.

TRK, (DVM, MPVM, PhD), is a veterinarian and Assistant Adjunct Professor for the UC Davis School of Veterinary Medicine. Her research focuses on the epidemiology of zoonotic pathogens and toxins at the animal-humanenvironment interfaces, and conservation medicine.

EK, (DVM, MS), is a veterinarian and research scientist at the Sokoine University of Agriculture.

WAS, (DVM, MPVM, PhD), is a veterinarian and an Associate Professor in the School of Veterinary Medicine, University of California, Davis. Her research focuses on the epidemiology of zoonotic pathogens at the human-animalenvironment interfaces in East Africa, Asia and North America.

RRK, (DVM, MVM, PhD), co-founder of the HALI Project, is a professor in the Department of Veterinary Medicine and Public Health at the Faculty of Veterinary Medicine and leads the Veterinary Public Health Unit at the Sokoine University of Agriculture.

JAKM, (DVM, MPVM, PhD), is the co-founder of the HALI Project together with Professor Rudovick Kazwala of the Sokoine University of Agriculture. She is a Professor of Wildlife Health and Epidemiology, Director of the One Health Institute at UC Davis, and Global Director of the USAID-funded PREDICT project. Her research programme focuses on the impacts of infectious diseases and toxins on wildlife populations with three major areas of emphasis: ecology of infectious diseases, coastal ecosystem health and wildlife diagnostics and disease surveillance.

\section{Acknowledgements}

Permission to conduct research was granted by the Tanzanian Commission for Science and Technology (COSTECH), Dar es Salaam, Tanzania (RCA 2008/ 129). Human subjects and animal handling protocols were permitted through the University of California, Davis, Institutional Review Board Protocol \#200816605-1 and Animal Care and Use Protocol \#12394. This research was supported through a Jim Ellis Mentorship Program for Graduate Students Award and an award for the Health for Animals and Livelihood Improvement Project, both through the Global Livestock Collaborative Research Support Program (GL-CRSP:), funded by the Office of Agriculture, Bureau for Economic Growth, Agriculture and Trade, United States Agency for International Development (USAID: https://www.usaid.gov/ ), under terms of Grant No. PCE-G-00-98-00036-00.

The opinions expressed herein are those of the authors and do not necessarily reflect the views of USAID. The funders had no role in the study design, data collection and analysis, decision to publish or preparation of the manuscript. This study was made possible thanks to the efforts of the HALI Project in Tanzania, especially Harrison Sadiki, Asha Makwete and Erasto Katowa. Special thanks also to all household participants for their generous hospitality and goodwill and to Alison Kent for the sentinel figure, Montague Demment for his council and support and Misty Richmond for her photography.

\section{Author details}

'One Health Institute, School of Veterinary Medicine, University of California, Davis, 1089 Veterinary Drive, Davis, CA, USA. ${ }^{2}$ California Department of Fish and Wildlife, Rancho Cordova, CA, USA. ${ }^{3}$ Faculty of Veterinary Medicine and Public Health, Sokoine University of Agriculture, Morogoro, Tanzania. ${ }^{4}$ Health for Animals and Livelihood Improvement (HALI) Project, http://www.haliproject.org.

\section{Received: 21 September 2015 Accepted: 1 June 2016}

\section{Published online: 04 July 2016}

\section{References}

Atwill, ER, Phillips R, and Rulofson F. 2003. Estimating environmental loading rates of the waterborne pathogenic protozoa, Cryptosporidium parvum, in certain domestic and wildlife species in California. University of California, Davis Sierra Foothill Research and Extension Center. (Available online: http://repositories.collib.org/anrrec/sfrec/sfrec_2003_atwill).

Barrington, G.M., J.M. Gay, and J.F. Evermann. 2002. Biosecurity for neonatal gastrointestinal diseases. The Veterinary Clinics of North America. Food Animal Practice 18: 7-34.

Bongartz, P., S.M. Musyoki, A. Milligan, and H. Ahsley. 2011. Tales of shit: Community led total sanitation in Africa - An overview. Participatory Learning and Action 61: 27-50
Bwire, B. 2011. Breaking shit taboos: CLTS in Kenya. Participatory Learning and Action 61: 91-96.

Cheneau, Y., A.H. El Idrissi, and D. Ward. 2004. An assessment of the strengths and weaknesses of current veterinary systems in the developing world. Revue Scientifique et Technique 23: 351-9.

Curtis, V., S. Caincross, and R. Yonli. 2000. Domestic hygiene and diarrhoea Pinpointing the problem. Tropical Medicine and International Health 5(1): 22-32.

Delafosse, A., J. Castro-Hermida, C. Baudry, et al. 2006. Herd-level risk factors for Cryptosporidium infection in dairy-goat kids in western France. Preventative Veterinary Medicine 77(1-2): 109-21.

Doherr, M.G., and L. Audige. 2001. Monitoring and surveillance for rare healthrelated events: A review from the veterinary perspective. Philosophical Transactions: Biological Sciences 356(1411): 1097-1106.

Donowitz, M., J.L. Barnett, and D.W. Powell. 1999. AGA technical review on the evaluation and management of chronic diarrhea. Gastroenterology 116: 1464-1486

DuPont, H.L., C.L. Chappell, C.R. Sterling, P.C. Okhuysen, J.B. Rose, and W. Jakubowski. 1995. The infectivity of Cryptosporidium parvum in healthy volunteers. New England Journal of Medicine 332: 855-9.

Everhart, J.E. (ed.). 1994. Digestive disease in the United States: Epidemiology and impact, 94-1447. Bethesda, MD: National Institutes of Health.

Fayer, R., L. Basbarre, P. Pasquali, A. Canals, S. Almeria, and D. Zarlenga. 1998 Cryptosporidium parvum infection in bovine neonates: Dynamic clinical, parasitic and immunologic patterns. International Journal of Parasitology 28: 49-56.

Graczyk, T.K., R. Fayer, and M.R. Cranfield. 1997. Zoonotic transmission of Cryptosporidium parvum: Implications for water-borne cryptosporidiosis. Parasitology Today 13(9): 348-351.

Halliday, J.E.B., A.L. Meredith, D.L. Knobel, D.J. Shaw, M. Bronsvoort, and S. Cleaveland. 2007. A framework for evaluating animals as sentinels for infectious disease surveillance. Journal of the Royal Society, Interface 4: 973-984.

Hosmer, D.W., and S.W. Lemeshow. 1989. Applied logistic regression, 307. New York, NY: Wiley.

Huetink, R.E.C., J.W.B. van der Giessen, J.P.T.M. Noordhuizen, and H.W. Ploeger. 2001. Epidemiology of Cryptosporidium spp. and Giardia duodenalis on a dairy farm. Veterinary Parasitology 102(1-2): 53-67.

Hunter, P.R., S. Hughes, S. Woodhouse, Q. Syed, N.Q. Verlaner, R.M. Chalmers, et al. 2004. Sporadic cryptosporidiosis case control study with genotyping Emerging Infectious Diseases 10: 1241-1249.

Jacob, M.O., K.O. Farah, and W.N. Ekaya. 2004. Indigenous knowledge: The basis of the Maasai ethnoveterinary diagnostic skills. Journal of Human Ecology 16(1): 43-48

Kasle, M. 2008. Neonatal diarrhea in the calf - Etiology and pathophysiology. Praktische Tierarzt 89(10): 852

Kotloff, K.L., J.P. Nataro, W.C. Blackwater, D. Nasrin, et al. 2013. Burden and aetiology of diarrhoeal disease in infants and young children in developing countries (the Global Enteric Multicenter Study, GEMS): A prospective, casecontrol study. Lancet 382: 209-222.

Kusiluka, L.J.M., E.D. Karimuribo, R.H. Mdegela, E.J. Luoga, P.K.T. Munishi, M.R.S. Mlozi, et al. 2005. Prevalence and impact of water-borne zoonotic pathogens in water, cattle, and humans in selected villages in Dodoma Rural and Bagamoyo districts, Tanzania. Physics and Chemistry of the Earth 30: 818-825.

Masozera, M. 2010. Ecosystem services and protected areas management in Africa (Doctoral Dissertation). Burlington: CATQuest: University of Vermont (Publication No. W15 O M3813m)

Mazet, J.A.K., D.L. Clifford, P.B. Coppolillo, A.B. Deolalkar, J.D. Erickson, and R.R. Kazwala. 2009. A "one health" approach to address emerging zoonoses: The HALI project in Tanzania. PLoS Medicine 6(12): e1000190.

McCluskey, B.J. 2003. Use of sentinel herds in monitoring and surveillance systems. In Animal disease surveillance and survey systems: Methods applications, ed. M.D. Salman, 119-133. Iowa, IA: lowa State Press.

Mfinanga, S.G.M., E. Ngadaya, R. Manungu, C. Makassy, et al. 2009. Baseline study for implementing community-based DOTS in pastoral communities in Tanzania 23. Dar es Salaam, Tanzania: National Institute for Medical Research (NIMR).

Miller, W.A., D. Clifford, R. Kazwala, A. Kitime, A. Kitambi, and J. Mazet. 2010. Fecal pathogen pollution in surface waters of the Ruaha ecosystem, Tanzania. Davis, CA: Global Livestock Collaborative Research Support Program, University of California Davis. Research Brief 10-03-HALI.

Minja, M.M.J. 1994. Towards networking among institutions and individuals working in the field of ethnoveterinary knowledge in Tanzania: Status of ethnoveterinary knowledge. LinKS project, gender, biodiversity and local knowledge systems for food security. In LinKS Report, 15, 34. Rome, Italy: Food and Agriculture Organization. 
Nsubuga, P., N. Eseko, T. Wuhib, N. Ndayimirije, et al. 2002. Structure and performance of infectious disease surveillance and response, United Republic of Tanzania, 1998. Bulletin of the World Health Organization 80(3): 196-203.

Olson, M.E., M. O'Handley, B.J. Ralston, T.Z. McAllister, and R.C.A. Thompson. 2004. Update on Cryptosporidium and Giardia infections in cattle. Trends in Parasitology 20(4): 185-191.

R Core Development Team. 2013. R: A language and environment for statistical computing. Vienna, Austria: R Foundation for Statistical Computing. ISBN 3-900051-07-0

Rabinowitz, P., M. Scotch, and L. Conti. 2009. Human and animal sentinels for shared health risks. Veterinaria Italiana 45(1): 23-24.

Richards, L., M. Claeson, and N.F. Pierce. 1993. Management of acute diarrhea in children: Lessons learned. Pediatric Infectious Disease Journal 12(1): 5-9.

Ryan, U., R. Fayer, and L. Xioa. 2014. Cryptosporidium species in humans and animals: Current understanding and research needs. Parasitology 141: 1667-1665.

Scheaffer, R.L., W. Mendenhall, and Ott R. Lyman. 2006. Stratified random sampling. In Elementary survey sampling, 6th ed, 117-179. Belmont, CA: Thomson Brooks/Cole.

Sergeant, ESG. 2015. Epitools epidemiological calculators. AusVet Animal Health Services and Australian Biosecurity Cooperative Research Centre on Emerging Infectious Disease. Available at http://epitools.ausvet.com.au.

Shears, P. 2000. Communicable disease surveillance with limited resources: The scope to link human and veterinary programs. Acta Tropica 76: 3-7.

Siwila, J., I.G.K. Phiri, J. Vercruysse, F. Goma, S. Gabriel, E. Claerebout, et al. 2007. Asymptomatic cryptosporidiosis in Zambian dairy farm workers and their household members. Transactions of the Royal Society of Tropical Medicine and Hygiene 101: 733-734.

Smith, R.P., F.A. Clifton-Hadley, T. Cheney, and M. Giles. 2014. Prevalence and molecular typing of Cryptosporidium in dairy cattle in England and Wales and examination of potential on-farm transmission routes. Veterinary Parasitology. doi:10.1016/j.vetpar.2014.05.022 [Epub ahead of print].

Snel, S.J., M.G. Baker, V. Kamalesh, N. French, and J. Learmonth. 2009. A tale of two parasites: The comparative epidemiology of cryptosporidiosis and giardiasis. Epidemiology and Infection 137: 1641-1650.

Strauss, A., and J. Corbin. 1998. Basics of qualitative research. Techniques and procedures for developing grounded theory, 312. California: Sage Publications, Inc.

Tanzania Ministry of Agriculture and Food Security. 2002. Agriculture sector development strategy. Dar es Salaam: Ministry of Agriculture and Food Security Tanzania.

Thornton, P.K., R.L. Kruska, N. Henninger, P.M. Kristjanson, R.S. Reid, F. Atieno, et al. 2002. Mapping poverty and livestock in the developing world. Nairobi: International Livestock Research Institute.

Tumwine, J.K., J. Thompson, M. Katua-Katua, M. Mujwajuzi, N. Johnstone, E. Wood and I. Porras. 2002. Diarrhoea and effects of different water sources, sanitation, and hygiene behaviour in East Africa. Tropical Medicine and International Health 7(9): 750-756.

United Nations Children's Fund (UNICEF)/World Health Organization (UNICEF/ WHO). 2009. Diarrhoea: Why children are dying and what can be done. New York, NY: UNICEF/WHO

Wudu, T., B. Kelay, H.M. Mekonnen, and K. Tesfu. 2008. Calf morbidity and mortality in smallholder dairy farms in Ada'a Liben district of Oromia, Ethiopia. Tropical Animal Health and Production 40(5): 369-376.

Xiao, L., and R.P. Herd. 1993. Quantification of Giardia cysts and Cryptosporidium oocysts in fecal samples by direct immunoflourescence. Journal of Clinical Microbiology 33: 2944-2946.

Zambrisky, J.A., D.V. Nydam, Z.J. Wilcox, D.D. Bowman, H.O. Mohammed, and J.L. Liotta. 2013. Cryptosporidium parvum: Determination of $\mathrm{ID}_{50}$ and the doseresponse relationship in experimentally challenged dairy calves. Veterinary Parasitology 197: 104-112.

\section{Submit your manuscript to a SpringerOpen ${ }^{\circ}$ journal and benefit from:}

- Convenient online submission

- Rigorous peer review

- Immediate publication on acceptance

- Open access: articles freely available online

- High visibility within the field

- Retaining the copyright to your article

Submit your next manuscript at $\gg$ springeropen.com 